Dementia

and Geriatric

Cognitive Disorders
Dement Geriatr Cogn Disord 2006;22:209-215

DOI: $10.1159 / 000094915$
Accepted: March 6, 2006

Published online: August 7, 2006

\title{
Prospective Memory Complaints Can Be Predicted by Prospective Memory Performance in Older Adults
}

\author{
Melanie Zeintl Matthias Kliegel Philippe Rast Daniel Zimprich \\ Department of Psychology, University of Zurich, Zurich, Switzerland
}

\section{Key Words}

Prospective memory - Prospective memory complaints •

Objective prospective memory performance

\begin{abstract}
Background/Aims: The aim of this study was to explore if prospective memory complaints reflect actual prospective memory performance in older adults. Methods: Three hundred and sixty-four older adults aged 65-80 years were investigated with regard to prospective memory complaints, prospective memory test performance, self-reported depressive symptoms, and self-reported memory capacity. $\boldsymbol{R e}$ sults: Separate analyses revealed that about half of the participants showed a significant relation between subjective and objective prospective memory. Conclusion: Older adults appear to be heterogeneous with regard to the association between objective and subjective prospective memory. For older adults with relatively few depressive symptomsandmemoryconcerns, prospectivememorycomplaints may serve as a valid criterion in the assessment of prospective memory ability.

Copyright $\odot 2006$ S. Karger AG, Basel
\end{abstract}

\section{Introduction}

Subjective memory complaints are common in later life. Previous research has shown that, usually, older adults hold more negative beliefs about their memory and report a greater frequency of forgetting than younger adults [1]. Consequently, memory complaints have become an important issue in research aiming at identifying older adults with a high risk of developing dementia [2].

The diagnostic relevance of subjective memory complaints, however, is still under debate. While some researchers have found older adults' metamemory to be quite accurate [3], the general finding is that there are no significant relations between self-reported memory and memory performance [4]. Additionally, there is evidence from various studies indicating that memory complaints are more highly correlated with emotional variables such as depressive symptoms than with actual memory performance $[5,6]$.

Although converging evidence shows that memory self-reports and objective memory performance are unrelated, previous research might have one important limitation. So far, studies investigating the significance of subjective memory complaints have focused on self-reported retrospective memory problems [7]. However, this might only reflect part of the phenomenon. A previous 
study on memory complaints in patients attending the Heidelberg Memory Clinic revealed that $40 \%$ of the patients spontaneously reported failures in remembering to do things as their main symptoms [8]. This type of memory is labeled prospective memory and has just started to become a focus of geriatric research [9]. Generally, the term prospective memory refers to the realization of delayed intentions [10], e.g. remembering to buy groceries on the way home from work, and there is evidence that the majority of everyday memory problems reported by healthy adults (even across the lifespan) may be prospective memory failures [11].

Despite their everyday prevalence, there is only limited research focusing specifically on prospective memory complaints [12]. Also, established memory questionnaires or diagnostic instruments on memory functioning do not include self-reported prospective memory as a separate construct $[11,13,14]$.

Apart from their everyday prevalence, prospective memory failures are characterized by quite serious consequences. First, intact prospective memory functioning is very important for everyday functioning, e.g. remembering to pay the telephone bill in time. Therefore, prospective memory performance is of great relevance for older adults' maintenance of an independent way of living [15]. Furthermore, prospective memory is of high social importance. Prospective memory failures may cause considerable embarrassment, as they are often attributed to a person's lack of reliability. For example, a person who forgets to call a good friend at her or his birthday may feel quite embarrassed when this memory failure becomes evident. By contrast, retrospective memory failures are rather ascribed to the weakness of a person's memory ability [16].

Taken together, subjective prospective memory appears to be an important but largely under-researched side of memory complaints across the lifespan. This is particularly relevant for older adults as they have to master a number of prospective memory tasks every day (e.g. remembering to take medication in time, remembering to switch off the stove after cooking, etc.) in order to maintain independence and autonomy in late life [17].

The first aim of this study, therefore, was to investigate if prospective memory complaints reflect objective prospective memory performance. The rationale for this assumption was that (due to the described prevalence and serious consequences of prospective memory failures) prospective memory complaints might be more closely related to actual performance than usually revealed regarding retrospective memory. In order to take into ac- count the general findings of high relations between noncognitive factors (e.g. emotional influences) and self-reported retrospective memory, the roles of depressive symptoms and general metamemory beliefs in prospective memory complaints were also considered.

Furthermore, there is initial evidence that the group of older adults might not be homogenous with regard to the predictor patterns of cognitive complaints [6]. In a recent study, two subgroups were identified via mixture regression analysis which significantly differed in the amount of reported cognitive complaints and depressive symptoms. Interestingly, cognitive performance was significantly related to cognitive complaints only in the subgroup showing fewer cognitive complaints and fewer depressive symptoms, whereas in the other subgroup actual performance had no effect on cognitive complaints [6]. Thus, the second aim of this study was to explore if prospective memory complaints might be differently related to the examined predictors depending on the amount of reported prospective memory complaints.

\section{Methods}

The present study is based on wave one data of the Zurich Longitudinal Study on Cognitive Aging (ZULU). The ZULU aims at examining the development of learning and cognitive functioning in healthy community-dwelling young-old adults.

\section{Sample}

Participants were mainly recruited through a random draw from the local registry of the city of Zurich, Switzerland, and constitute a largely representative sample. Only native speakers of German with intact vision and hearing were included. Participants were screened for cognitive impairments and excluded in case of potential dementia (MMSE < 24). Data were collected from 364 older adults between 65 and 80 years of age (age: mean $=73.0$ years; $\mathrm{SD}=4.43$ ), with $46 \%$ of the sample being female. The average subjective health rated on a 6-point Likert-type scale ( 1 = 'very poor' to $6=$ 'excellent') was between 'rather good' and 'good' (mean $=4.83$; SD $=0.81$ ). Participants were provided with written and oral descriptions of the study outline and written informed consent was obtained. The study was conducted in agreement with the declaration of Helsinki [18].

Assessment of Subjective Prospective Memory Complaints

To assess subjective prospective memory complaints, the Prospective and Retrospective Memory Questionnaire (PRMQ) [11] was applied. The PRMQ is the first subjective memory measure that systematically assesses prospective memory complaints. It has been demonstrated to have good psychometric properties [11, 19, 20].

All participants were given the Prospective Scale of the PRMQ, which consists of eight items describing everyday situations of prospective memory failures, e.g., 'I often fail to mention or give 
something to a visitor that I was asked to pass on'. For each item, participants were requested to indicate on a 5-point Likert-type rating scale ( 1 = 'agree strongly' to $5=$ 'disagree strongly') to what extent the described memory failure applied to them. The ratings from the 8 items were added to result in a score from 8 to 40, with higher scores representing fewer prospective memory complaints. The reliability of the Prospective Scale as measured by internal consistency has been found to be acceptable (Cronbach alpha = $0.84)$ [19].

Assessment of Depressive Symptoms and Metamemory Beliefs

In order to assess the degree of negative affect, the Geriatric Depression Scale (GDS) [21] was applied. The GDS is a self-report measure of depressive symptoms in the elderly and has been used and tested extensively with older adults [22]. In the present study, participants were given the Short Form of GDS, which contains 15 questions enquiring about different depressive symptoms, e.g. 'Do you often feel helpless?' [22]. Participants were supposed to give a yes or no answer to each question. The answers to the 15 questions were summed up to form a score from 0 to 15 , with higher scores indicating more depressive symptoms. The Short Form of GDS has shown an acceptable internal consistency (Cronbach alpha $=0.78)[23]$.

Metamemory beliefs were assessed using the Capacity Scale of the Metamemory in Adulthood (MIA) Questionnaire [24]. Selfreported memory capacity was assessed by 11 items containing statements about one's own general memory functioning. Note that all items of the Capacity Scale focus on retrospective memory capacity, e.g. 'I am good at remembering names' (reverse scored). Participants were supposed to indicate on a 5-point Likert-type rating scale ( 1 = 'agree strongly' to 5 = 'disagree strongly') to what extent they agreed with each memory statement. The ratings from the 11 items were accumulated to give a memory capacity score ranging from 11 to 55 , with higher scores indicating better self-reported memory capacity. The Capacity Scale of the MIA has shown an acceptable internal consistency (Cronbach alpha = 0.86) [24].

Assessment of Objective Prospective Memory Performance

A standard prospective memory laboratory task [25] was applied in order to measure prospective memory performance. The Red Pencil task was initially described by Dobbs and Rule [26]. Participants were supposed to remember to repeat the words 'red pencil' whenever the experimenter mentioned these words [27]. This occurred three times during the testing session. The instruction for the prospective memory task was given at the beginning of the 2-hour testing session, in which a large cognitive test battery was applied. Participants were asked to immediately repeat the instruction in order to ensure that they had understood the task. In accordance with standard prospective memory procedures [25], the Red Pencil task was distributed over the whole testing session. Prospective memory performance was scored as the proportion of correct responses out of three possible reactions, with higher scores indicating better performance. The Red Pencil task has shown a high internal consistency (Cronbach alpha $=$ 0.93) [27].

\section{Statistical Analyses}

To assess whether prospective memory complaints were related to actual prospective memory test performance and/or to noncognitive variables, correlations between prospective memory complaints and Red Pencil task scores, GDS scores, and memory capacity scores were calculated for the complete sample. Additionally, the sample was split at the median (which was comparable to the mean score) of Prospective Scale scores of the PRMQ into prospective memory high complainers and prospective memory low complainers [12]. Since the mean and variance scores of the present sample were comparable to those found in a validation study of the PRMQ [19], high complainers can be regarded as reporting an above-average amount of prospective memory complaints, and low complainers as reporting a below-average amount. It was examined if the two subgroups might show a differential association pattern with regard to the assessed variables. In order to further explore the results of the correlational analyses, separate multiple linear regression analyses were performed for the entire sample and for the two subgroups, i.e. prospective memory high complainers and low complainers, controlling for age, education, and sex.

\section{Results}

In table 1, descriptive information about the total sample, prospective memory high complainers, and low complainers is provided. The sample was split at the median of the Prospective Scale scores (30.00) into prospective memory high complainers and low complainers. Particularly, the two subgroups were compared with regard to prospective memory test performance, depressive symptoms, and self-rated memory capacity. Results show that prospective memory high complainers, who reported more prospective memory failures than low complainers, did not significantly differ from the low complainers in prospective memory test performance. However, prospective memory high complainers had significantly higher GDS scores and significantly lower self-reported memory capacity scores than low complainers. The reliabilities (assessed by Cronbach alpha) were 0.72 for the Prospective Scale of the PRMQ, 0.86 for the Red Pencil task, 0.74 for the GDS, and 0.82 for the Capacity Scale of the MIA.

\section{Correlations of Prospective Memory Complaints with \\ Prospective Memory Test Performance, Depressive \\ Symptoms, and Memory Capacity}

Table 2 displays the results of correlational analyses for the complete sample as well as for prospective memory high complainers and low complainers separately. Results for the complete sample showed that prospective memory complaints were significantly related to GDS scores and self-reported memory capacity, but not to objective prospective memory test performance. Participants who reported more prospective memory failures also tended to report more depressive symptoms and a poorer memory 
Table 1. Descriptive characteristics of the total sample, prospective memory high complainers, and low complainers

\begin{tabular}{lccc}
\hline & Total $(\mathrm{n}=364)$ & \multicolumn{2}{l}{ PM complainers } \\
\cline { 3 - 4 } & & high $(\mathrm{n}=197)$ & low $(\mathrm{n}=167)$ \\
\hline PM complaints score, mean \pm SD & $29.77 \pm 4.91(17-40)$ & $26.30 \pm 3.65$ & $33.87 \pm 2.39$ \\
Age, mean \pm SD, years & $73.04 \pm 4.43(65-80)$ & $73.15 \pm 4.30$ & $72.91 \pm 4.59$ \\
Education, mean \pm SD, years & $12.83 \pm 3.03(2-23)$ & $12.86 \pm 3.16$ & $12.79 \pm 2.88$ \\
Sex, male/female & $196 / 168$ & $106 / 91$ & $90 / 77$ \\
PM test performance , mean \pm SD & $0.42 \pm 0.44(0-1)$ & $0.41 \pm 0.43$ & $0.43 \pm 0.44$ \\
GDS score, mean \pm SD & $1.64 \pm 2.01(0-14)$ & $2.14 \pm 2.31^{\mathrm{b}}$ & $1.04 \pm 1.39^{\mathrm{b}}$ \\
Memory capacity score, mean \pm SD & $34.79 \pm 7.15(19-54)$ & $32.63 \pm 6.74^{\mathrm{c}}$ & $37.33 \pm 6.78^{\mathrm{c}}$ \\
\hline
\end{tabular}

$\mathrm{PM}=$ Prospective memory; $\mathrm{SD}=$ standard deviation. Ranges are displayed in parentheses.

a Proportion correct.

${ }^{b}$ Means significantly different at $\mathrm{p}<0.01$ (Mann-Whitney test).

${ }^{\mathrm{c}}$ Means significantly different at $\mathrm{p}<0.01$ (t test).

Table 2. Correlations of prospective memory complaints (Prospective Scale score) with objective prospective memory performance, depressive symptoms and self-reported memory capacity

\begin{tabular}{lccc}
\hline & Total $(\mathrm{n}=364)$ & \multicolumn{2}{c}{ PM complainers } \\
\cline { 3 - 4 } & & high $(\mathrm{n}=197)$ & low $(\mathrm{n}=167)$ \\
\hline Age $^{\mathrm{a}}$ & 0.01 & 0.04 & 0.06 \\
Education in years $^{\mathrm{a}}$ & -0.03 & -0.00 & -0.09 \\
Sex $(\mathrm{m}=0 ; \mathrm{f}=1)^{\mathrm{b}}$ & -0.04 & -0.04 & -0.09 \\
PM test performance $^{\mathrm{c}}$ & 0.09 & 0.08 & $0.21^{* *}$ \\
GDS score $^{\mathrm{a}}$ & $-0.38^{* *}$ & $-0.32^{* *}$ & $-0.15^{*}$ \\
Memory capacity score $^{\mathrm{a}}$ & $0.36^{* *}$ & $0.22^{* *}$ & 0.12 \\
\hline
\end{tabular}

${ }^{*} \mathrm{p}<0.1$, significant (two tailed); ${ }^{* *} \mathrm{p}<0.01$, significant (two tailed).

a Pearson correlations.

b Point-biserial correlation.

${ }^{\mathrm{c}}$ Spearman correlation. capacity. However, separate analyses for prospective memory high complainers and low complainers revealed a different picture. While the association pattern of prospective memory high complainers was similar to that found for the complete sample, prospective memory low complainers showed no statistically significant relation between self-rated memory capacity and prospective memory complaints and only a marginally significant relation between GDS scores and prospective memory complaints (table 2). Instead, a significant relationship was found for prospective memory test performance and prospective memory complaints. Within the prospective memory low complainers, those who reported fewer prospective memory failures also tended to show better prospective memory test performance.
Multiple Linear Regression Analyses with Prospective Memory Complaints as the Criterion

Multiple linear regression analyses predicting prospective memory complaints (with depressive symptoms, self-rated memory capacity, and prospective memory test performance as predictors as well as age, education, and sex controlled for) showed that, when entered simultaneously, depressive symptoms and self-rated memory capacity were the only significant predictors of prospective memory complaints for the complete sample $[\mathrm{F}(6,357)=$ $17.80, \mathrm{p}<0.001$; adjusted $\left.\mathrm{R}^{2}=0.22\right]$. For the group of prospective memory high complainers, the same results were found as for the complete sample, with GDS scores and self-rated memory capacity being the only significant predictors $\left[\mathrm{F}(6,190)=5.23, \mathrm{p}<0.001\right.$; adjusted $\left.\mathrm{R}^{2}=0.12\right]$. 
However, consistent with the correlational analyses described above, a different pattern emerged for prospective memory low complainers. Here, besides an effect of age, prospective memory test performance was the only significant predictor of prospective memory complaints $\left[\mathrm{F}(6,160)=3.71, \mathrm{p}<0.01 ;\right.$ adjusted $\left.\mathrm{R}^{2}=0.09\right]$.

\section{Discussion}

The first aim of the present study was to explore if selfreported prospective memory complaints reflect actual prospective memory performance in older adults. To the authors' knowledge, this is the first study that investigates the association between objective and subjective prospective memory in a large sample of older adults. Considering the correlation and regression analyses for the complete sample, on first inspection findings do not seem to indicate a strong relation between prospective memory complaints and actual prospective memory performance. The results seem to corroborate findings from retrospective memory research, where, as converging evidence from a number of studies has shown, relations between actual memory performance and self-referent memory assessments are small ${ }^{1}$ [4]. Thus, also personal judgments about one's own prospective memory performance are to be interpreted with caution.

However, considering previous work $[6,12]$, examining the sample as a whole might not be an accurate approach for the investigation of underlying processes of subjective memory complaints. Therefore, the second aim of this study was to examine if prospective memory complaints might be differently related to the examined predictors depending on the amount of prospective memory complaints being reported by participants.

Initial analyses showed that although participants from both groups scored very similarly on the prospective memory task, high complainers reported significantly more prospective memory failures than low complainers. In fact, the results of the differential correlation and regression analyses revealed that in the low complainer

\footnotetext{
1 Our own results on the association pattern between self-reported retrospective memory (MIA Capacity Scale), depressive symptoms, and objective memory performance (Word List Recall [28]) correspond with the well-confirmed finding that subjective and objective retrospective memory are only weakly related. For the complete sample as well as for the subgroups, we found significant associations of self-reported retrospective memory capacity with depressive symptoms, but not with objective retrospective memory performance (results are comparable when using the median of the Prospective Scale or the median of the Capacity Scale as criterion for forming the subgroups).
}

Prospective Memory Complaints in Old Age group subjective prospective memory complaints were significantly related solely to prospective memory task performance. This result is inconsistent with the general notion that subjective prospective memory judgments are inaccurate in general, since in almost half of the participants, prospective memory self-reports reflected objective prospective memory performance.

Furthermore, since subjective memory capacity judgments were not related to prospective memory complaints in the low complainer group, at least in those individuals subjective metamemory beliefs regarding retro- and prospective memory appear to be dissociable. The remaining participants, i.e. the high complainer group, showed an association pattern similar to the one found for the complete sample. Prospective memory complaints were significantly associated with depressive symptoms and selfreported memory capacity, but not with prospective memory test performance.

Overall, the findings of the present study are similar to the results obtained by Kliegel and Zimprich [6] who identified two subgroups of older adults differing in the relation between cognitive performance and cognitive complaints. They propose that if depression and neuroticism are less pronounced, the influence of other variables such as actual performance may emerge. This conclusion might be transferred in part to the findings in the present study. Prospective memory performance may only constitute a predictor of prospective memory complaints when depressive symptoms are scarce.

An open issue discussed in research on subjective retrospective memory is the possibility that discrepancies between memory self-ratings and memory performance may arise because, generally, performance in laboratorybased memory tasks is compared with self-ratings on memory questionnaires that enquire about daily, memory-relevant situations. Thus, due to insufficient ecological validity, performance in formal memory tasks might not be representative of memory experiences in everyday situations, which guide memory self-ratings in memory questionnaires [29]. These concerns may also apply to research on prospective memory complaints. Taking into consideration that the questionnaire items of the PRMQ enquire about everyday prospective memory failures, it may be arguable if laboratory-based measures like the Red Pencil task are representative of the everyday prospective memory performance assessed by the memory questionnaire. This problem may lead to an attenuation of the effects found. Therefore, additional studies using more naturalistic prospective memory tasks might be helpful in order to further clarify this issue. 
Finally, it has to be noted that the presented results refer to young-old adults (65-80 years of age) only. There is evidence that, especially from the age of 80 years, there is a pronounced decline in prospective memory performance [30]. This might lead to a higher sensitivity to prospective memory problems and may result in a better selfappraisal of prospective memory in adults over the age of 80 years. Therefore, further research on old-old adults ( $>80$ years of age) is needed in order to enhance the understanding of the association patterns between objective prospective memory performance and subjective prospective memory complaints in old age.

In sum, the results of the present study indicate that young-old adults seem to be heterogeneous with regard to the predictor patterns of prospective memory complaints. While for about half of the participants, actual prospective memory performance was a significant predictor of prospective memory complaints, for the remaining participants the relation between objective and subjective prospective memory seems to be masked by depressive symptoms. Thus, it can be concluded that for a considerable number of young-old adults - characterized by comparably lower levels of depressive symptoms and memory complaints - self-reported prospective memory complaints might serve as a valid additional criterion in the assessment of prospective memory ability. This result is of enormous clinical relevance as there is evidence that prospective memory impairment in older adults may be a very early indicator of dementia and that prospective memory tasks seem to be more susceptible to the early stages of dementia than retrospective memory tasks [3133]. The present study provides initial evidence that it might be possible to use prospective memory complaints as an indicator of actual prospective memory performance in a large group of older adults. Further research is needed to achieve a better understanding of the conditions under which prospective memory ability can be deduced from self-reported prospective memory.

\section{Acknowledgement}

This research was supported by funding from the Swiss National Science Foundation.

\section{References}

1 Gilewski MJ, Zelinski EM, Schaie KW: The memory functioning questionnaire for assessment of memory complaints in adulthood and old age. Psychol Aging 1990;5: 482-490.

-2 Bischkopf J, Busse A, Angermeyer MC: Mild cognitive impairment: a review of prevalence, incidence and outcome according to current approaches. Acta Psychiatr Scand 2002;106:403-414.

$\checkmark 3$ Jonker C, Launer LJ, Hooijer C, Lindeboom J: Memory complaints and memory impairment in older individuals. J Am Geriatr Soc 1996;44:44-49.

4 Hertzog C, Hultsch DF: Metacognition in adulthood and old age; in Craik FIM, Salthouse TA (eds): Handbook of Aging and Cognition, ed 2. Mahwah, Lawrence Erlbaum Associates, 2000, pp 417-466.

5 Zimprich D, Martin M, Kliegel M: Subjective cognitive complaints, memory performance, and depressive affect in old age: a changeoriented approach. Int J Aging Hum Dev 2003;57:339-366

6 Kliegel M, Zimprich D: Predictors of cognitive complaints in older adults: a mixture regression approach. Eur J Ageing 2005;2:1323.
7 Derouesné C, Lacomblez L, Thibault S, LePoncin M: Memory complaints in young and elderly subjects. Int J Geriatr Psychiatry 1999;14:291-301.

-8 Kliegel M, Martin M: Prospective memory research: why is it relevant? Int J Psychol 2003;38:193-194.

-9 Kazui H, Matsuda A, Hirono N, Mori E, Miyoshi N, Ogino A, Tokunaga $\mathrm{H}$, Ikejiri $\mathrm{Y}$ Takeda M: Everyday memory impairment of patients with mild cognitive impairment. Dement Geriatr Cogn Disord 2005; 19:331337.

10 Ellis J: Prospective memory or the realization of delayed intentions: a conceptual framework of research; in Brandimonte $M$, Einstein GO, McDaniel MA (eds): Prospective Memory: Theory and Applications. Mahwah, Lawrence Erlbaum Associates, 1996, pp 1-22.

11 Smith G, DellaSala S, Logie RH, Maylor EA: Prospective and retrospective memory in normal ageing and dementia: a questionnaire study. Memory 2000;8:311-321.

12 Mäntylä T: Assessing absentmindedness: prospective memory complaint and impairment in middle-aged adults. Mem Cognit 2003;31:15-25.

13 Pfluger M, Aebi C, Monsch AU: Germanlanguage version of the CERAD neuropsychological test battery. Z Klin Psychol Psychother 2003;32:64-66.
14 Gilewski MJ, Zelinski EM: Questionnaire assessment of memory complaints; in Poon LW (ed): Handbook for Clinical Memory Assessment of Older Adults. Washington, American Psychological Association, 1986, pp 93-107.

15 Maylor EA: Does prospective memory decline with age?; in Brandimonte M, Einstein GO, McDaniel MA (eds): Prospective Memory: Theory and Applications. Mahwah, Lawrence Erlbaum Associates, 1996, pp 173197.

16 Winograd E: Some observations on prospective remembering; in Gruneberg MM, Morris PE, Sykes RN (eds): Practical Aspects of Memory: Current Research and Issues. Chichester, Wiley, 1988, vol 1, pp 348-353.

17 Cockburn J, Smith PT: Anxiety and errors of prospective memory among elderly people. Br J Psychol 1994;85:273-282.

18 World Medical Organization: Declaration of Helsinki. BMJ 1996;313:1448-1449.

19 Crawford JR, Smith G, Maylor EA, Della Sala $\mathrm{S}$, Logie $\mathrm{RH}$ : The prospective and retrospective memory questionnaire (PRMQ): Normative data and latent structure in a large non-clinical sample. Memory 2003;11:261275 . 
20 Crawford JR, Henry JD, Ward AL, Blake J: The prospective and retrospective memory questionnaire (PRMQ): latent structure, normative data and discrepancy analysis for proxy-ratings. Br J Clin Psychol, in press.

-21 Yesavage JA, Brink TL, Rose TL, Lum O, Huang V, Adey M, Leirer VO: Development and validation of a geriatric depression screening scale: a preliminary report. J Psychiatr Res 1983;17:37-49.

22 Sheikh JI, Yesavage JA: Geriatric depression scale (GDS): recent evidence and development of a shorter version. Clin Gerontol 1986;5:165-173.

23 Steiner A, Raube K, Stuck AE, Aronow HU, Draper D, Rubenstein LZ, Beck JC: Measuring psychosocial aspects of well-being in older community residents: performance of four short scales. Gerontologist 1996;36:5462.
24 Dixon RA, Hultsch DF, Hertzog C: The metamemory in adulthood (MIA) questionnaire. Psychopharmacol Bull 1988;24:671688.

25 Wilson B, Cockburn J, Baddeley AD, Hiorns $\mathrm{R}$ : The development and validation of a test battery for detecting and monitoring everyday memory problems. J Clin Exp Neuropsychol 1989;11:855-870.

26 Dobbs AR, Rule BG: Prospective memory and self-reports of memory abilities in older adults. Can J Psychol 1987;41:209-222.

27 Salthouse TA, Berish DE, Siedlecki KL: Construct validity and age sensitivity of prospective memory. Mem Cognit 2004;32:11331148.

28 Helmstädter C, Lendt M, Lux S: Verbaler Lern- und Merkfähigkeitstest. Göttingen, Lelitz Test, 2001.

-29 Hertzog C, Park DC, Morrell RW, Martin M: Ask and ye shall receive: behavioural specificity in the accuracy of subjective memory complaints. Appl Cogn Psychol 2000;14: 257-275.
30 Kliegel M, Jäger T: Delayed-execute prospective memory performance: the effects of age and working memory. Dev Psychol, in press.

31 Huppert FA, Beardsall L: Prospective memory impairment as an early indicator of dementia. J Clin Exp Neuropsychol 1993;15: 805-821.

>32 Huppert FA, Johnson T, Nickson J: High prevalence of prospective memory impairment in the elderly and in early-stage dementia: findings from a population-based study. Appl Cogn Psychol 2000;14:S63-S81.

33 Maylor EA, Smith G, Della Sala S, Logie RH: Prospective and retrospective memory in normal aging and dementia: an experimental study. Mem Cognit 2002;30:871-884. 